ORIGINAL ARTICLE

\title{
Rationing in the emergency department: the good, the bad, and the unacceptable
}

\author{
E Cross, S Goodacre, A O'Cathain, J Arnold
}

Emerg Med J 2005;22:171-176. doi: 10.1136/emj.2004.020180

See end of article for authors' affiliations

.....................

Correspondence to: Elizabeth Cross, Health Services Research, School of Health and Related Research, University of Sheffield, Sheffield, S1 4DA, UK; e.a.cross@ sheffield.ac.uk

Accepted

28 November 2004

\begin{abstract}
Objectives: Waiting times in emergency departments (EDs) are an important government priority. Although substantial efforts are currently being made to reduce waiting times, little attention has been paid to the patients' view. We used qualitative methods to explore patients' perspectives on waiting times and other approaches to rationing and prioritisation.

Methods: Face to face, in depth, qualitative interviews $(n=11)$ explored how patients valued waiting times for non-urgent ED care. The framework approach (identifying a thematic framework through repeated rereading) was used to analyse transcripts.

Results: Interviewees found some forms of rationing and prioritisation acceptable. They expected rationing by delay, but required explanations or information on the reason for their wait. They valued prioritisation by triage (rationing by selection) and thought that this role could be expanded for the re-direction of nonurgent patients elsewhere (rationing by deflection). Interviewees were mainly unwilling or unable to engage in prioritisation of different types of patients, openly prioritising only those with obvious clinical need, and children. However, some interviewees were willing to ration implicitly, labelling some attenders as inappropriate, such as those causing a nuisance. Others felt it was unacceptable to blame "inappropriate" attenders, as their attendance may relate to lack of information or awareness of service use. Explicit rationing between services was not acceptable, although some believed there were more important priorities for NHS resources than ED waiting times. Interviewees disagreed with the hypothetical notion of paying to be seen more quickly in the ED (rationing by charging).

Conclusions: Interviewees expected to wait and accepted the need for prioritisation, although they were reluctant to engage in judgements regarding prioritisation. They supported the re-direction of patients with certain non-urgent complaints. However, they perceived a need for more explanation and information about their wait, the system, and alternative services.
\end{abstract}

$\mathrm{T}$ he reduction of waiting times in emergency departments (EDs) is an important government priority in the UK. Although substantial efforts are currently being made to reduce waiting times, it is likely that ED staff will continue to have to manage queues of patients waiting for treatment. Long waiting times are a form of rationing and can be viewed in the context of a range of rationing strategies, including rationing by delay, denial, deterrence, dilution, selection, deflection, substitution, termination, and charges. ${ }^{2}$ A further type of rationing operating in EDs is that of triage systems, which are used to prioritise attenders in EDs, and which might be classed as rationing by selection, given that patients who are triaged as non-urgent have been shown to have higher walkout rates. ${ }^{3}$ Judgements about rationing are made by those formulating government policy and delivering services, but what do patients themselves think about these issues? Quantitative patient satisfaction surveys have shown that patients are unhappy with the length of time they wait for treatment, ${ }^{45}$ but have offered little insight into patients' views of different rationing strategies in EDs. Qualitative methods can access information that quantitative methods fail to reach, ${ }^{6}$ and are becoming a valuable approach to exploring important issues within EDs. ${ }^{78}$ Therefore, we undertook a qualitative study to explore patients' views of different rationing strategies in EDs.

\section{METHODS}

The study was undertaken at the Northern General Hospital, which provides adult ED services to the population of Sheffield (530 000), and sees approximately 90000 new adult attendances per year. Subjects gave written informed consent, and ethics approval was obtained from the North Sheffield local ethics research committee. We used purposive sampling to reflect the diversity of ED attendees, sampling patients of differing ages, sex, and socioeconomic status, attending for non-life threatening illnesses or injuries, ${ }^{9}$ and during time periods when there were both long and short waiting times in the ED. Once patients had been booked in and triaged, the ED cards were briefly scanned for patient demographics, reason for attendance, triage categories of 3-5 (where 5 is lowest priority), and length of wait. This was carried out by the researcher to exclude approaching potentially inappropriate patients, such as those with mental health concerns.

"Selected" patients sitting in the waiting room were then approached during the researcher's working week: Monday to Friday, between 0900 and 1900, during the 3 month period of August to October 2002. They were contacted within a week of their visit, and a convenient time was then arranged to visit them at their home or workplace. Face to face semistructured interviews were carried out by one author (EC) not affiliated to the ED. All interviewees gave informed consent and agreed to the interview being taped. The interview schedule was developed in discussion between clinicians and researchers, and it worked effectively, allowing discussion of the relevant issues and flexibility in practice. It covered patients' views of their recent visit to the ED, waiting times in the ED in general, government spending on EDs and the NHS, prioritisation of patients of different ages or with

Abbreviation: $E D$, emergency department 
varying severity of injury, patients being turned away, patient charges, and the triage process. The final section of the interview involved the presentation of a scenario of 15 types of patients that could be triaged by the interviewee, and moved up or down the queue (fig 1). These scenarios were based upon experiences of clinicians in an ED and also a review of the guidelines on triage by the Manchester Triage Group. ${ }^{9}$

In qualitative studies, a small sample provides a large amount of data that require extensive analyses. This study does not aim to be generalisable or statistically representative. The method of selecting interviewees aimed to provide diversity of patient types and offer deeper insights into people's views of waiting in EDs.

\section{Analysis}

The interviews were transcribed verbatim by EC. The data were analysed using framework analysis. ${ }^{10}$ Although the general approach in this analysis is inductive, it also allows for the inclusion of both a priori and emergent concepts. ${ }^{11}$ Using this approach, familiarisation with each interview was firstly achieved by reading each transcript several times. Varying themes were identified, for example, "expectations": "I thought I was going to get seen then virtually straight away but I didn't" (Case 08); “acceptability": "You choose to either wait or you go home, don't you?" (Case 04); and "negativity": "Feel insignificant and made to feel a nuisance for being there" (Case 07). Two transcripts (randomly selected) were then discussed in detail with another member of the research team (AOC) to identify a thematic framework. Each transcript (case) was coded in relation to these themes. Case charts (matrices) were then drawn up to plot out the themes. This allowed clear, visual interpretation of the whole dataset via the identified themes. Common themes were then identified across cases. We grouped and categorised the common underlying themes and also noted issues that were not common across the cases. The thematic framework was refined and re-categorised, linking related themes together; for example, "expectations", "lack of information/ uninformed", and "comparison with past experiences" were all categorised as "education/awareness" during this process. We then returned to the transcripts to view the data in the context of these themes, a process known as recontextualisation. ${ }^{12}$

\section{RESULTS}

For the study , 27 patients were approached in the ED waiting room, and 11 agreed to be interviewed (Table 1).

Of the 27 patients approached in the waiting room to be interviewed, five, aged in their twenties, declined to take part (four male, one female). Others declined to be interviewed at home, but offered to be interviewed in the hospital while they were waiting to be seen. Unfortunately, this was not practical. Interviewees reported waits varying between 1 and 5 hours (table 2 ).

\section{The acceptability of waiting times: the role of expectations and information}

There appeared to be an acceptance of rationing by delay in the ED. When considering their own waiting times in the ED, interviewees' tolerance of waiting seemed to be related to their expectations. They knew that there were often long waits in the ED, and thus expected to wait themselves. This expectation arose from their own previous experiences, or those of their relatives, friends, or neighbours. For example, one interviewee had been "pleasantly surprised" that he did

Imagine that you are the assessing nurse in the A\&E department.
You are assessing each of the following types of patient and can change their position in the queve
according to the results of your assessment.
You have five options for each type of patient (see Options below)
- Children
- Illnesses that could be seen by the patient's GP e.g. sore throats
- Elderly people
- Life threatening conditions e.g. heart attack, fitting, uncontrolled bleeding
- Very painful conditions (that can't be controlled by tablets) e.g. elderly lady fallen and hurt hip
- Patients with conditions that could get worse if not treated within an hour e.g. fracture/dislocation
- Satients who are creating a disturbance or making a fuss
- Patients who have been injured at work
- Smoking related illnesses
- Drug abuse related injuries
- Injuries that were sustained more than a day ago
- Bleeding (that is not life threatening) e.g. small cut to leg
- Patients who are under police arrest
Patients who are drunk
Are there any other groups of patients you can think of that you might want to move up or down the
queve?
Options

Figure 1 Interview scenarios. 


\begin{tabular}{|c|c|c|c|}
\hline $\begin{array}{l}\text { ED } \\
\text { user }\end{array}$ & $\begin{array}{l}\text { Age } \\
\text { group }\end{array}$ & Sex & Result \\
\hline 1 & $60-64$ & $M$ & Interviewed \\
\hline 2 & $25-29$ & M & Declined \\
\hline 3 & $55-59$ & $\mathrm{~F}$ & Interviewed \\
\hline 4 & $20-24$ & M & Declined \\
\hline 5 & $50-54$ & $\mathrm{~F}$ & Declined \\
\hline 6 & $20-24$ & M & Declined \\
\hline 7 & $55-59$ & $\mathrm{~F}$ & No phone/ declined \\
\hline 8 & $35-39$ & M & Interviewed \\
\hline 9 & $65-69$ & $\mathrm{~F}$ & Declined \\
\hline 10 & $30-34$ & $\mathrm{~F}$ & Declined \\
\hline 11 & $45-49$ & M & Interviewed \\
\hline 12 & $20-24$ & $\mathrm{~F}$ & Declined \\
\hline 13 & $55-59$ & $\mathrm{~F}$ & Declined \\
\hline 14 & $60-64$ & M & Declined \\
\hline 15 & $55-59$ & $\mathrm{~F}$ & Declined \\
\hline 16 & $55-59$ & M & Declined \\
\hline 17 & $25-29$ & M & Declined \\
\hline 18 & $40-44$ & $\mathrm{~F}$ & Interviewed \\
\hline 19 & $60-64$ & $\mathrm{~F}$ & Interviewed \\
\hline 20 & $40-44$ & M & Declined \\
\hline 21 & $30-34$ & M & Declined \\
\hline 22 & $30-34$ & M & Declined \\
\hline 23 & $70-74$ & M & Interviewed \\
\hline 24 & $55-59$ & $\mathrm{~F}$ & Interviewed \\
\hline 25 & $50-54$ & $\mathrm{~F}$ & Interviewed \\
\hline 26 & $35-39$ & M & Interviewed \\
\hline 27 & $20-24$ & M & Interviewed \\
\hline
\end{tabular}

not wait as long as expected on the Tuesday following a bank holiday Monday, even though he waited a total of 3.5 hours (Case 01).

"Whenever I've had to go it's always been the same that it's been a long wait, because obviously people that are more urgent get put first, which is only right" (Case 09).

Despite others being unhappy about the length of their wait, the main concern expressed was the lack of information about why they were waiting. Comments were made about not knowing what was going on behind closed doors, why some patients who had waited less time than others were seen first, or why sometimes no one appeared to be treated at all. Interviewees suggested that further information should be made available to those waiting, possibly displaying posters in the waiting area outlining the order of priority of different illnesses or injuries.

"You don't know how many staff are dedicated to A\&E.

They could all be at lunch" (Case 03).

Additionally, interviewees seemed unaware of the ways in which EDs might function; for example, that emergency ambulances brought patients to the same department, and that these emergencies affected the time that patients wait to be seen. In the ED in this study, patients in the waiting room could not see ambulance staff arriving with emergency patients, and this may have contributed to their perception that at times no one was being treated.

\section{Prioritisation and rationing: the good, the bad, and the unacceptable}

The prioritisation process of triage was considered to be a valuable process that, on the whole, worked well. Interviewees seemed to trust the triage decision: "They've a good idea, haven't they really?" (Case 04). Suggestions were made about increasing the role of the triage nurse to diagnose so that patients did not have to see a doctor or could be recommended to seek care from a more appropriate service. That is, interviewees found rationing by selection acceptable, and suggested the expansion of triage to include rationing by dilution (in that everyone would not see a doctor) and rationing by deflection to other services.

Although interviewees agreed with the concept of prioritisation within triage, they were less positive about the concept of rationing by sending patients away without seeing a doctor or nurse, because of the potential risk of turning away someone who was seriously ill. Overall, they accepted that some inappropriate attenders should be re-directed to other services or "de-prioritised", specifically attenders with non-urgent complaints, who could be seen by a general practitioner.

"Where there's definitely no other complications, then yes, they should be turned away because it is using time that other people probably need. But there's always the other side of it, that, is that just the problem or could it be anything worse?" (Case 09).

"You'd have to check them slightly in case of a brain tumour or heart attacks or something. You do hear horror

\begin{tabular}{|c|c|c|c|c|c|c|c|}
\hline Case & Sex & $\begin{array}{l}\text { Age } \\
\text { group }\end{array}$ & $\begin{array}{l}\text { Educational } \\
\text { level attained }\end{array}$ & $\begin{array}{l}\text { Reason } \\
\text { for ED } \\
\text { aftendance }\end{array}$ & TC & $\begin{array}{l}\text { Wait to see doctor } \\
\text { reported by patient }\end{array}$ & Total wait \\
\hline 01 & $M$ & $60-64$ & School & Knee injury & 4 & $3 \mathrm{~h}(3 \mathrm{~h} 18 \mathrm{~min})$ & $31 / 2 \mathrm{~h}(3 \mathrm{~h} 28 \mathrm{~min})$ \\
\hline 02 & M & $35-39$ & $\begin{array}{l}\text { Further } \\
\text { education }\end{array}$ & Eye injury & 4 & $1 \mathrm{hr}(1 \mathrm{~h} 19 \mathrm{~min})$ & $\begin{array}{l}11 / 2 \text { to } 11 / 4 \mathrm{~h}(1 \mathrm{~h} \\
34 \mathrm{~min})\end{array}$ \\
\hline 03 & $M$ & $45-49$ & School & Fall & 3 & $3 / 4 \mathrm{hr}(3 / 4 \mathrm{hr})$ & $1 \mathrm{hr}(1 \mathrm{~h} 12 \mathrm{~min})$ \\
\hline 04 & $\mathrm{~F}$ & $55-59$ & School & Fall & 4 & $<4 \mathrm{~h}(3 \mathrm{~h} 19 \mathrm{~min})$ & $4 \mathrm{~h}(3 \mathrm{~h} 29 \mathrm{~min})$ \\
\hline 05 & $\mathrm{~F}$ & $40-44$ & School & RTA & 5 & $4 \mathrm{~h}(3 \mathrm{~h} 39 \mathrm{~min})$ & 5 h (4 h $39 \mathrm{~min})$ \\
\hline 06 & $\mathrm{~F}$ & $60-64$ & School & Leg pain & 4 & $11 \frac{1}{2} \mathrm{~h}(1 \mathrm{~h} 19 \mathrm{~min})$ & $2 \mathrm{~h}(1 \mathrm{~h} 44 \mathrm{~min})$ \\
\hline 07 & $\mathrm{~F}$ & $55-59$ & $\begin{array}{l}\text { Higher } \\
\text { education: }\end{array}$ & Rib injury & 4 & $11 / 4 \mathrm{~h}(1 \mathrm{~h} 43 \mathrm{~min})$ & $2 \mathrm{~h}$ (1 h $52 \mathrm{~min})$ \\
\hline 08 & M & $70-74$ & School & $\begin{array}{l}\text { Painful big } \\
\text { toe }\end{array}$ & 4 & $3 \mathrm{~h}(2 \mathrm{~h} 33 \mathrm{~min})$ & $3 \frac{1}{2} \mathrm{~h}(2 \mathrm{~h} 36 \mathrm{~min})$ \\
\hline 09 & $\mathrm{~F}$ & $44-49$ & School & Painful rib & 4 & $2 \mathrm{~h}(1 \mathrm{~h} 57 \mathrm{~min})$ & $2 \frac{1}{4} 4 \mathrm{~h}(2 \mathrm{~h} 07 \mathrm{~min})$ \\
\hline 10 & M & $35-39$ & $\begin{array}{l}\text { Higher } \\
\text { education }\end{array}$ & RTA & 4 & $13 / 4 \mathrm{~h}(2 \mathrm{~h} 02 \mathrm{~min})$ & $2^{1 / 2} \mathrm{~h}(2 \mathrm{~h} 07 \mathrm{~min})$ \\
\hline 011 & M & $20-24$ & $\begin{array}{l}\text { Further } \\
\text { education }\end{array}$ & Painful wrist & 4 & $4 \mathrm{~h}(2 \mathrm{~h} 31 \mathrm{~min})$ & $4^{1 / 4} \mathrm{~h}(3 \mathrm{~h})$ \\
\hline
\end{tabular}


stories that someone was told they had indigestion or panic attacks" (Case 03).

A less acceptable form of rationing within the context of the NHS was the hypothetical notion of paying to be seen more quickly in the ED as a way of controlling demand. All interviewees raised the issue of equity; that it would be unfair on those who could not afford to pay. However, having raised this point, some interviewees said that they would pay, depending on the seriousness of the complaint, the level of pain, and the cost. One interviewee said he could afford to pay and would go private if there was a remit for accident and emergency care in private health care.

\section{"It's like a public service in a way, and I don't think you should have to [pay]" (Case 011). \\ "It depends if you can afford it. Probably most people can' $^{\prime \prime}{ }^{\prime \prime}$ (Case 04).}

Whereas triage was an acceptable mode of prioritising within EDs, they found the whole concept of rationing between EDs and other services totally unacceptable. Interviewees were willing to discuss whether the government should spend more money on reducing waiting times in EDs; some felt that the government should, while others suggested greater priorities such as reducing waiting lists. However, when asked which services should lose resources in order that EDs gain, interviewees were unable or unwilling to participate in this explicit rationing, instead wanting more money to be directed into the NHS as a whole.

\section{"I think more money should be put into the health service full stop." (Case 01)}

\section{Patients: the good, the bad, and the unacceptable}

When presented with the scenarios of 15 types of patients and asked whether they would change their position in the queue, interviewees were mainly unwilling or unable to prioritise types, preferring to leave most patients where they were in the queue. They did not appear comfortable with making judgements, stating that this decision could only be made by clinical staff. However, they were willing to engage in prioritisation for some patient types, in particular that those with clinical need defined as threat to life, extreme pain, or potential for deterioration should be moved up the queue.

\section{"It's not about how you've injured yourself but how serious it is" (Case 07).}

Regardless of the seriousness of the complaint, they advocated moving children up the queue because they could be more upset and less able to understand the situation than adults, and there could also be uncertainty over the seriousness of their complaint. They did not express similar concerns for the other end of the age spectrum, tending to leave elderly patients where they were in the queue.

\section{"Well you have to look after a child, well, for one, they soon get upset, a child gets upset, and I think they should be seen you know...quite quickly." (Case 08).}

Some types of patients were judged as having lower priority than others, in particular those who were considered to have contributed to their illness or injury, for example those with injuries related to smoking or drug misuse, and sports injuries. However, interviewees who themselves were in these categories were, unsurprisingly, less likely to make negative judgements about this type. Patients under the influence of alcohol were not favourably looked upon. Some interviewees found it acceptable to send these people away without treatment while others took a pragmatic approach of moving them up the queue to get them seen as quickly as possible to reduce the chance of disturbance or trouble.

Although some interviewees were willing to label others as inappropriate attenders, they did not want to be seen as inappropriate attenders themselves. When discussing whether those with non-urgent complaints should be turned away, some felt the need to justify their own attendance at the ED.

"I felt bad last week about going... but I was in so much pain" (Case 06).

The themes of blame and information merged at this point. Interviewees considered that it was not a patient's fault if they tried to use an ED and did not know they could have gone to a minor injuries unit (MIU) or walk in centre, for example. They felt that these services should be better publicised, and if patients were turned away then they should receive explanations about the appropriate use of EDs and other services.

\section{"There needs to be better awareness and education generally" (Case 07)}

\section{DISCUSSION}

In this study, ED patients found some forms of rationing more acceptable than others, and offered ways in which current forms of rationing could be made more acceptable. Implicit forms of rationing in operation in EDs, such as rationing by delay, could be made more acceptable to patients if they were informed about the length of delay and reasons for it, and how an ED functioned. They were in favour of triage even though this is a means of rationing by selection. Interviewees suggested that other forms of rationing could be used more, such as rationing by deflection-that is, patients could be informed to go to other services, as long as they were not blamed for not knowing to go there in the first place. They were also in favour of rationing by dilution, as they were happy to see an increasing role for the triageur so that not everyone saw a doctor. This has been attempted elsewhere. ${ }^{13}$ However, interviewees found explicit rationing difficult to engage with, and saw risks in rationing by denial (although they were willing to accept it if the risks could be reduced) and problems in rationing by charging, such as introducing inequity. They preferred to leave judgements about waiting times for most types of patients to staff, although were able to prioritise patients with clinical need, echoing Cookson \& Dolan's study. ${ }^{14}$ Children were given universal priority, linking in with Dingwall's work that children break rules used by staff in EDs but are not punished for it. ${ }^{15}$ Interviewees also gave lower priority to people with self inflicted injuries or illnesses, although empathy and past experiences diluted this effect.

Although reluctant to engage with prioritising different types of patients, in some instances interviewees made similar judgements to ED staff. Good patients were characterised by their medical seriousness and bad patients by social characteristics, for example patients under the influence of alcohol who were disruptive, or under arrest. ${ }^{16}$ There were also some important differences. For example, interviewees could justify why an attendance at an ED was 
appropriate after waiting a number of days with a condition, while this category might be labelled as "trivia" by staff. Interviewees seemed aware that staff might consider them to be "inappropriate" attenders, or "time wasters", a label that can cause distress and give a sense of being treated badly, and one that patients have been shown to work hard at avoiding having it applied to them. ${ }^{17}$ To some extent, they shifted this blame back to staff and services by making the point that it was not the fault of the patient if they did not know of the most appropriate service to attend. An ignorance of alternative services to EDs has been found elsewhere, ${ }^{18} 19$ and this would not be the first study to suggest that people need educating about alternatives to EDs. A study of choice between EDs and general practice "out of hours" centres demonstrated that, once informed about another service (in this case a GP co-operative), most ED attenders were willing to use that service in the future. ${ }^{18}$ However, it is acknowledged that most ED attenders only frequent EDs once every 4 years.

This study confirmed the findings of quantitative studies of patient views of ED services that patient satisfaction with waiting times is related to their expectations. ${ }^{20-22}$ This study has also confirmed that waiting could be made more acceptable and satisfaction increased if information is provided about reasons for waiting. ${ }^{23-25}$ Of course, it may simply have been more acceptable for interviewees to express concerns about information in the context of a "public" interview, rather than appear selfish by demanding shorter waits. However, this appeared to be a genuine plea and seems to be a relatively simple and resource free solution that EDs could put into operation. Similarly, more general information, via posters or leaflets, about how an ED functions might be valued by patients and improve satisfaction. ${ }^{26-28}$ Although this study has confirmed findings of previous studies, many of them relate to EDs in the USA. ${ }^{20-23} 252629$ This study adds a UK perspective. ${ }^{30}$

\section{Limitations}

Although purposive sampling was used, we were restricted by ethical, resource, and feasibility issues. Undertaking the interviews during the daytime may have excluded some types of patients from the interviews, and caused some people, particularly men and younger people, to decline participation owing to time constraints or discomfort with face to face interviews. At the other end of the age continuum, only one older person (70-75 years) was approached and interviewed. Logistically it was more difficult to approach older people in the waiting area, and there were also ethical considerations, as older people may be more distressed. Our approach was a convenient way of sampling but it had its shortcomings. Given more time and resources in future studies, alternative ways of approaching patients would be appropriate.

Face to face interviewing captures interviewees' accounts, ${ }^{31}$ but does this method inhibit responses? In this study, people may have been wary about expressing views that seemed selfish or lacking in humanity. EC sometimes felt within the interviews that people were offering socially acceptable answers to some of the rationing questions. If this study had surveyed views using questionnaires, then interviewees may have felt more comfortable expressing less socially acceptable views but, conversely, less detailed insight would have been gained.

Interviewees' experiences and behaviour naturally influenced their responses, for example, those who smoked, those attending with sports related injuries, or with injuries sustained more than a day previously. Some were defensive about these factors, or unhappy about their wait, which may have influenced their perceptions and views.
The timing of the interview may have influenced the findings. Perceptions reported 1 week post-attendance may differ to those immediately post-attendance. Although perceptions may change over time, there is no reason to suppose that perceptions recorded at one time are any more valid than those recorded at another time. We consistently interviewed patients after a similar length of time postattendance, where possible.

\section{Implications for future research/clinical practice}

This study has identified some possible trade offs with waiting times that could be further explored by quantitative methods such as conjoint analysis. ${ }^{32}{ }^{33}$ Providing information may be of as much value to patients as decreasing actual waiting time. Some forms of rationing, such as waiting times and triage are acceptable, but people find it difficult to engage in explicit rationing of services in terms of denying treatment, taking money from one service to pay for another, or asking patients to pay. These may be unacceptable in the context of the NHS, but may be more acceptable outside it, for example the existence of a private ED in the south of England.

\section{CONTRIBUTORS}

SG conceived and designed the study. SG, EC and AOC prepared the interview schedule. EC co-ordinated the study, with JA and EC recruiting the interviewees and EC conducting the interviews. EC transcribed and analysed the data, in discussion with AOC and SG. EC wrote the paper, with involvement from AOC. AOC and SG contributed towards editing the paper. All authors contributed to the final draft.

\section{Authors' affiliations}

E Cross, A O'Cathain, Health Services Research, School of Health and Related Research, University of Sheffield, Sheffield, UK

S Goodacre, J Arnold, Accident and Emergency Department, Northern General Hospital, Sheffield, UK

Competing interests: none declared

\section{REFERENCES}

1 The Audit Commission. Acute hospital portfolio: accident and emergency. London: The Audit Commission, 2001.

2 Arksey H. Rationed care: assessing the support needs of informal carers in english social services authorities. In: Klein R, Day S, Redmayne S, eds. Managing scarcity: priority setting and rationing in the National Health Service. Buckingham: Open University Press, 1996:81-101.

3 Mohsin M, Bauman A, leraci S. Is there equity in emergency medical care? Waiting times and walk-outs in South Western Sydney hospital emergency departments. Aust Health Rev 1998;21:3.

4 Goldwag R, Berg A, Yuval D, et al. Predictors of patient dissatisfaction with emergency care. Isr Med Assoc J 2002;4:603-6.

5 Waseem M, Ravi L, Radeos M, et al. Parental perception of waiting time and its influence on parental satisfaction in an urban pediatric emergency department: are parents accurate in determining waiting time? South Med J 2003;96:880-3.

6 Pope C, Mays N. Reaching the parts other methods cannot reach: an introduction to qualitative methods in health and health services research. BMJ 1995;311:42-5.

7 Olsson $M$, Hansagi $\mathrm{H}$. Repeated use of the emergency department: qualitative study of the patient's perspective. Emerg Med J 2001;18:430-4.

8 Lloyd G, Skarratts D, Robinson N, et al. Communication skills training for emergency department senior house officers - a qualitative study. J Accid Emerg Med 2000;17:246-50.

9 Manchester Triage Group. Emergency triage. London: BMJ Publishing, 1997.

10 Ritchie J, Spencer L. Qualitative data analysis for applied policy research. In: Bryman, Burgess, eds. Analysing qualitative data. London: Routledge, 1997:173-94.

11 Pope C, Ziebland S, Mays N. Analysing qualitative data. BM 2000;320:114-16.

12 Dey I. Qualitative data analysis: a user-friendly guide for social scientists. London: Routledge, 1993.

13 Cheung WW, Heeney L, Pound JL. An advance triage system. Accid Emerg Nurs 2002;10:10-16.

14 Cookson R, Dolan P. Public views on health care rationing: a group discussion study. Health Policy 1999;49:63-74.

15 Dingwall R, Murray T. Categorisation in accident departments: 'good' patients, 'bad' patients and 'children'. Sociol Hlth Illn 1983;5: 128-48. 
16 Jeffery R. Normal rubbish: deviant patients in casualty departments. Sociol Hlth Illn 1979;1:90-107.

17 Goode J, Hanlon G, O'Cathain A, et al. Risk and the responsible health consumer: the problematics of entitlement among callers to NHS Direct. Critical Social Policy 2004;24:210-32.

18 Rajpar SF, Smith MA, Cooke MW. Study of choice between accident and emergency departments and general practice centres for out of hours primary care problems. J Accid Emerg Med 2000;17:18-21.

19 Vazquez QB, Pardo MG, Fernandez CG, et al. Why do our patients go to hospital emergency departments? Atencion Primaria 2000;25:172-5.

20 Thompson DA, Yarnold PR. Relating patient satisfaction to waiting time perceptions and expectations: the disconfirmation paradigm. Acad Emerg Med 1995;2:1057-62.

21 Trout A, Magnusson AR, Hedges JR. Patient satisfaction investigations and the emergency department: What does the literature say? Acad Emerg Med 2000;7:695-709.

22 Hedges JR, Trout A, Magnusson AR. Satisfied patients exiting the Emergency Department (SPEED) study. Acad Emerg Med 2002;9:1-21.

23 Bruce TA, Bowman JM, Brown ST. Factors that influence patient satisfaction in the emergency department. J Nurs Care Qual 1998;13:31-7.

24 Frank-Soltysiak M, Court C. Waiting time and satisfaction of patients attending the emergency surgery unit of a university hospital center. Presse Medicale 2002;31:1690-5.
25 Thompson DA, Yarnold PR, Williams DR, et al. Effects of actual waiting time, perceived waiting time, information delivery, and expressive quality on patient satisfaction in the emergency department. Ann Emerg Med 1996;28:657-65

26 Krishel S, Baraff $\sqcup$. Effect of emergency department information on patient satisfaction. Ann Emerg Med 1993;22:568-72.

27 Kologlu M, Agalar F, Cakmakci M. Emergency department information: does it affect patients' perception and satisfaction about the care given in an emergency department? Eur J Emerg Med 1999;6:245-8.

28 Nelson D, Coleman K, Walker J. Why are you waiting? Formulating an information pamphlet for use in an accident and emergency department. Accid Emerg Nurs 1997;5:39-4.

29 Bursch B, Beezy J, Shaw R. Emergency department satisfaction - what matters most. Ann Emerg Med 1993;22:586-91.

30 Maitra A, Chikhani C. Waiting times and patient satisfaction in the accident and emergency department. Arch Emerg Med 1993;10:388-9.

31 Baruch G. Moral tales: parents' stories of encounters with the health professionals. Sociol Hlth Illn 1981;3:275-95.

32 leung GM, Chan SSC, Chau PYK, et al. Using conjoint analysis to assess patients' preferences when visiting emergency departments in Hong Kong Acad Emerg Med 2001;8:894-8

33 Morgan A, Shackley P, Pickin M, et al. Quantifying patient preferences for out-of-hours primary care. J Health Serv Res Policy 2000;5:214-18. 